\title{
Microfinance, the Role and Impact on Macroeconomic Indicators of the Country. Case study: Albania
}

\author{
Phd. Candidate, Esmeralda Doçi12 \\ Department of Finance and Accounting, Agricultural University of Tirana, Albania \\ Email: esmeralda.doci@yahoo.com
}

Doi:10.5901/mjss.2017.v8n1p161

\begin{abstract}
Microcredit or microfinance are one of the most important novelties on development policy in the last 25 years. Most of the recent studies are based on the impact that microfinance has on poverty reduction or on the income on macroeconomic level. Due to lack of data on microfinance on a macro level, studies of their impact on poverty are limited. However, they have recently analysed the link between microeconomics and microfinance activity, which has shown significant connectivity between the operations of Micro Financial Institutions and Macroeconomic indicators.Microfinance in Albania has developed and this is demonstrated by the presence of Micro Financial Institutions which have contributed to poverty reduction and to economic development in general, and to agricultural development in particular. The purpose of the study is to analyse the importance and the relationship between microfinance and macroeconomic indicators, the impact that microfinance has on macroeconomic indicators. Based on previous literature researchers and empirical studies, this study aims to analyse empirically the relationship between the gross portofolio of MFIs and macroeconomic factors. Specifically, to analyse whether a country with high level of credit portfolio provided by Micro Financial Institutions has low poverty and macroeconomic factors taken into analysis, considering the endogeneity of the gross portfolio of Micro Fianancial Institutions. The empirical evaluation and analysis is carried out through econometric evaluation using the EViews program.
\end{abstract}

Keywords: microfinance, microfinance activity, credit portfolio, macroeconomic factors, econometric evaluations, regression analysis

\section{Introduction}

Microfinance has grown fast since the 1970s, in order to attenuate the poverty and to stimulate the economic growth. However, in recent decades, microfinance has undergone many transformations and nowadays it represents an important industry in the industry of self-financing institutions, which have reported to have more than 3,000 institutions of microfinance, with 154 million customers worldwide (Microcredit Summit Campaign, 2009). Micro financial Institutions (MFIs) are concentrated mainly in developed countries, which present an effective way to regulate or balance the level of poverty in order to improve the standard of living, through investments in businesses or their education(Snerc and Svobodová, 2009). Most owners of these "businesses" are poor farmers who need and want to improve or expand their business, which lack liquidity. Meanwhile, in recent years, microfinance has grown steadily in Albania. Micro financial institutions have credited more than 350.000 small entrepreneurs and families throughout Albania, injecting over 1 billion dollars into the national economy. It's also noted a growth of the gross loan portfolio with $5.6 \%$ and the growth of the costumers served. One of the priorities of MFIs are the rural areas and the provision of service for credit or deposit in a segment of the population that lives in remote areas of the country and that cannot be accessed from other financial institutions, also the empowerment of women in entrepreneurship.

\section{Microfinance and the Impact of Macroeconomic Factors According to Previous Studies}

The study of microfinance, specifically the analysis of the impact of microfinance in macroeconomic indicators is a "trend" on the rise in today's literature. Recently, they have analyzed the link between macroeconomics and micro financial activities or the micro financial performance such as Ahlin et al. (2010), Ahlin and Lin (2006) Kai and Hamori(2009) ect. The analysis of macroeconomic factors that determine an unequal distribution of MFIs and the impact of aggregates of a country such as GDP, inflation, poverty and corruption (Marconi \& Mosley, 2005; Honohan, 2004 2008; Vanroose, 2007,

${ }^{1}$ Note: This study is part of the dissertation's topic of Msc. Esmeralda Doçi ( PHD Candidate)

2Supervisor of General Budget and Investment in Reserve Found - Social Insurance Institute , Albania. 
2008; Vanroose \& D ' Espallier, 2009).The impact of microfinance in the economy growth is perceived through direct and indirect channels:

- The direct impact of microfinance is based on poverty reduction, increased welfare and the impact on the value added to gross production through entrepreneurial activities of the poor. Therefore, microfinance is seen as a direct contribution to the economic growth (Maksudova, 2010).

- $\quad$ The indirect impact, is seen on the contribution that microfinance has on the development of the banking system. The rival interaction of microfinance in the banking sector has contributed to the growth and the maturity of the financial sector (Cull et al, 2009, Hermes et al, 2009).

The chart below shows the dynamic of microfinance, based on the impact of MFIs in the macroeconomic and financial indicators.

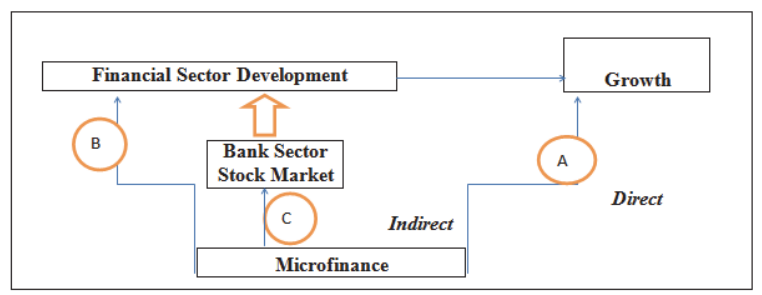

Chart 1. Microfinance's dynamics

Overall, the macroeconomic environment is important to the future performance of MFIs (Ahlin and Lin 2006). A growing GDP contributes to the development of the country, at the same time, it leads to high profitability of MFls themselves. This interaction is inverse, because these institutions affect the growth of GDP, loans given for financial support help the overall economic growth (Maksudova, 2010).Janda and Zetek(2014) have found that macroeconomic factors have a significant impact in influencing interest rates of the microfinance institutions. These factors have a significant impact on the overall profitability of the MFIs. An increase in the number of borrowers, usually affects the proportional growth of the size of the loan portfolio. Real interest rates, the rates that the banks charge for the financial services they offer, affect the interest rates of MFIs, and also the loan portfolio of MFIs. The choice of these variables at the macroeconomic level is based on previous findings discussed at macroeconomic level, and connected to our questions about macroeconomic factors and their ability to influence the performance of microfinance.

\section{The Performance of Micro Financial Institutions in Albania}

A growing micro financial activity and the increasing presence of $\mathrm{MFI}^{3} \mathrm{~S}$ are noted during the last years. The sustainable development of these institutions, given the important role that microfinance has on creating the opportunities to access the sources of funding for many people, for small and medium enterprises, has been repeatedly the focus of the policy of the Bank of Albania. The development of MFls has fuelled interest in knowing and better understanding the macroeconomic environmental elements and factors that have contributed to this growth. However, microfinance in Albania has developed and this is demonstrated by the presence of Micro Financial Institutions which have contributed to poverty reduction and to economic development in general, and to agricultural development in particular.

Microfinance has developed in Albania; this is noted by the presence of microfinance institutions that have contributed to poverty reduction and economic development in general and agricultural development in particular. Lending to the agricultural sector in the portfolio of bank loans represents the least credit sector compared to other sectors, benefiting around $2 \%$ of the total loan portfolio, extended to the Albanian economy. Given the need of the agricultural sector for financing or credit, today there are financial institutions that provide financial services to the agricultural sector, such as microfinance institutions that offer credit, but nowadays many banks of the second level are promoting and competing with each other in terms of new service of microfinance / credit of the agricultural sector.

The chart below shows some statistical data on the gross loan portfolio of MFIs, comparing GLP, the number of

${ }^{3}$ According to MIX Market, the term "micro financial institutions" is referred to micro financial institutions specialized on the crediting field such as non-bank subjects, credit unions and savings, licensed institutions of microcredit. There are 36 functioning savings and loans companies, 3 non-bank financial institutions and 4 credit foundations in Albania. 
MFls and the number of the active borrowers in our country to the regional countries. The study of these data is carried out at regional level too.

Compared to the countries of the region that our country is compared to, we see that the presence of microfinance institutions, the micro financial activities and the number of the barrowers is low. The level of these indicators remains low.

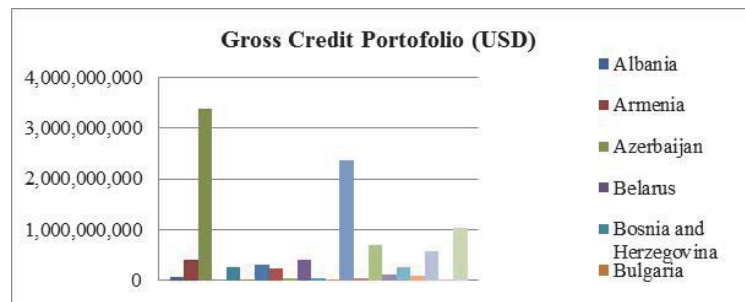

Chart 2. Gross Credit Portfolio by Eastern Europe and Central Asia

Source: Cross- Market Analysis, MIX Market, author's calculation

The Gross portfolio of loans provided by MFIs in the country amounts to 53,475,625 USD. Compared to other regional countries, our country has the lowest amount of the loan portfolio.

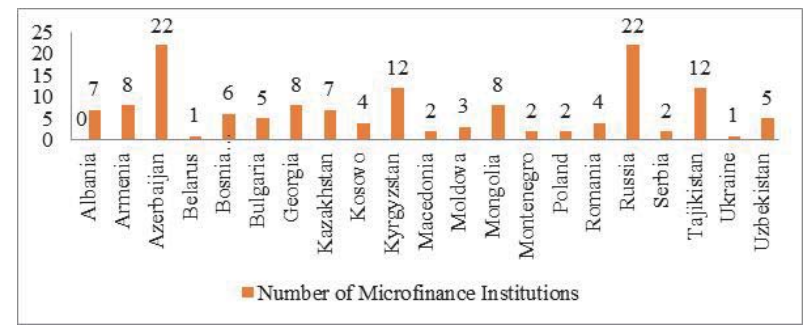

Chart 3. Number of microfinance institutions by Eastern Europe and Central Asia

Source: Cross- Market Analysis, MIX Market, author's calculation

The number of MFI in our country reaches 7 institutions, compared to the Balkan countries, we have a positive indicator, and however the highest number of MFIs is in Azerbaijan and Russia.

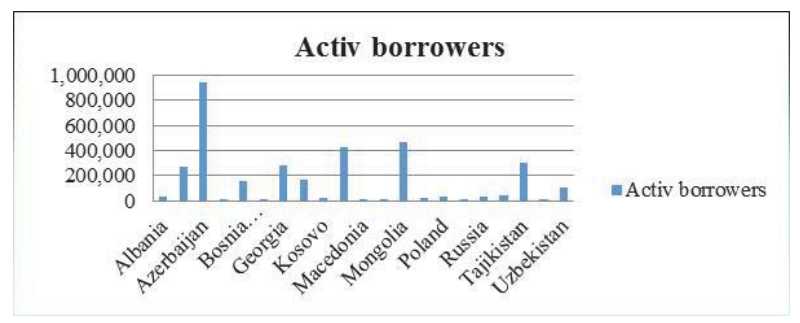

Chart 4. The number of borrowers by Eastern Europe and Central Asia

Source: Cross- Market Analysis, MIX Market, author's calculation

The number of active barrowers in the Microfinance institutions is high, as mentioned before in Azerbaijan, in our country it doesn't exceed 50,000 barrowers. Compared to Kosovo and Bosnia and Herzegovina we have a higher number of barrowers. 


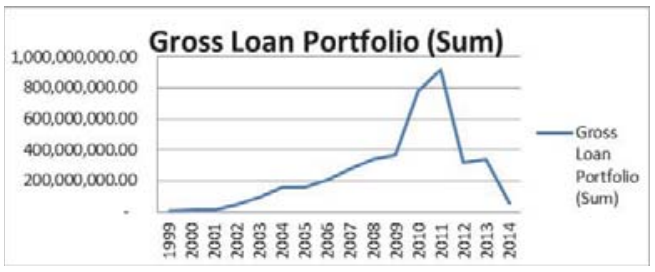

Chart 5.Gross loan portfolio of microfinance institution in Albania,from 1999-2014

Source: Cross- Market Analysis, MIX Market, author's calculation

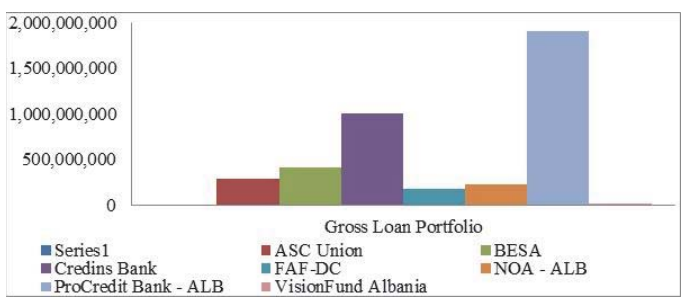

Chart 6. The portfolio of loans provided by financial institutions, from 1999-2013

Source: Cross- Market Analysis, MIX Market, author's calculation

\section{Methodology}

Measuring the degree of the rate sensitivity of the banking system against unforeseen losses that may be caused by the process of loan repayment, is quite difficult. However, continuous efforts have been made to build empirical models, which measure the extent of the impact of different macroeconomic variables on such indicators that show important evidence of the non-banking system's performance, such as the loan portfolio of microfinance institutions etc. The purpose of the study is to analyse the importance and the relationship between microfinance and macroeconomic indicators, the impact that microfinance has on macroeconomic indicators. portfolio.

Basic assumption of the problem: The macroeconomic factors have an important impact on the quality of the credit

The problem analysis is focused on the study of the link between the macroeconomic factors of our country and the loan portfolio of MFIs in econometric level. The study has followed the next steps:Initially, we focused on building the adequate econometric model and the econometric analysis of the impact of macroeconomic factors in the loan portfolio of MFIs in Albania from 1999 to 2014. Through these analysis we have succeeded in formulating the best model which defines the form and economic link between variables, consistent with the economic theory.During the econometric analysis, we were based on the analysis of the economic problem, following the steps of the econometric analysis since the introduction of the problem, the evaluation and the testing of the statistical hypothesis.Also, after the evaluation and the testing of the assumed model is done, the study continues with the analysis of the ARIMA model of the loan portfolio.

\subsection{Source of data}

Time series for this paper are taken from the World Bank database, Bank of Albania and MIX ${ }^{4}$. The bases of the used data are annual. The access of the time series data on gross loan portfolio for the developed countries is very difficult. The data segment on the loan portfolio of microfinance institutions operating in Albania is narrow. The data used in the model starts from 1999 until 2014.

There are used two indicators regarding the microfinance activity: the loan portfolio yield - as a dependent variable, and the number of the active customers of the micro financial institutions (MFIs). The number of the active borrowers is used as a weighting factor or as one of the expository variables. Other variables included in the model are Gross Domestic Product, (GDP), Inflation and the Real Interest Rate of the lender.Empirical analysis of the problem is based in

${ }^{4}$ Microfinance Information Exchange(MIX Market) 
the usage of econometric statistical methods, namely Eviews program. In the annex section you will find the econometric models realized with Eviews.

\subsection{Model rate}

The form of assumed model in our study is the link between yield on gross portfolio (real) and macroeconomic indicators. The model is presented as below:

$Y \_R=\beta 0+\beta 1 * \mathrm{GDP}+\beta 2 *$ Inflation $+\beta 3 * \mathrm{NoAB}+\beta 4 *$ Interest_Real $+u$

$Y$ Y R - Yield on gross portfolio (real) -Yield on Gross Portfolio (nominal) - Inflation Rate)/(1 + Inflation Rate)

GDP- Annual percentage growth rate of Gross Domestic Product

NoAB - Number of active borrowers

Inflation- Inflation consumer prices (annual \%)

Interest_Real - Real lending interest rate

Moreover, inthe study we have evaluated the series of yield gross portfolio. To do this evaluation we have used the ARIMA model. With this model series is explained by itself and does not take into account any other factor to the variation of this series explained too. ARIMA model is a combination of three mechanisms:

AR- Autoregressive -is an model that express the variable in relation with himself but with different dynamic delay; $\left(Y_{-} R t-\delta\right)=\alpha 1\left(Y_{-} R t-1-\delta\right)+e t$

$\delta$-is the average of $Y_{-} R t(e)$ is the error term not correlated that has average zero and constant variance, otherwise known as white Buzzer.

I - Integrated- means that the series has to be stationary, if it is' stationary it must return such by "filtrations" passing from the original series in the series of differences chain.

$\Delta Y_{-} R t=\delta Y_{-} R t-1+e t$

$\delta=\rho-1 \rho$ - is the coefficient correlations ranked first, which takes values from [-1, 1]. If $Y \_R t$ turn stationery we can say that the series is integrated.

MA- Moving Average- sliding averages model; $Y_{-} R t=\mu+\beta 0 e t+\beta 1$ et -1

$Y$ in $t$ time is equal to a constant with sliding average of current term error and of a previous period. Specifically our model ARIMA related to $Y \_R t$ will be:

$$
Y_{-} R t=\left\{\begin{array}{c}
A R(p)-\left(Y_{-} R t-\delta\right)=\alpha 1\left(Y_{-} R t-1-\delta\right)+e t \\
I(d)-\Delta Y_{-} R=\delta Y_{-} R t-1+e t \\
M A(q)-Y_{-} R t=\mu+\beta o e t+\beta 1 \text { et }-1
\end{array}\right\}
$$

The databases used in this section are in percentages, particularly from 1999 - 2014.

\section{Problem Analysis}

Since we are dealing with dynamic time series to estimate reliability and evaluation of assumed model, it is important to determine if we are dealing with stationary series or not. Using regression methods used in the time series provided that the series is stationary, or else the results of the evaluation model assumed by Fischer or "student" tests might be discussed and we will have unreliable results. To discover if the series are stationary or not there are several methods, but in our study is used Philip Peron method, which is as Dickey Fuller simple method, but as the dependent variable is $\mathrm{D}$ (yield on gross portfolio) and independent variable is yield on gross portfolio with dynamic delay, but has a constant in problem treatment.

Through Eviews we have estimated the model and calculate relevant indicators as follow:

$\Delta\left(Y_{-} R t\right)=0.0164-0.8727 Y_{-} R_{t-1}+e_{t}$

Where:

Y_R $\mathrm{R}_{\mathrm{t}-1}$ - yield on gross loan portfolio(real) with first order of dynamic delay

$\Delta\left(Y_{-} R\right)-$ Chain difference of yield on gross loan portfolio(real)

\begin{tabular}{lllc} 
& & Adj. t-Stat & Prob.* $^{*}$ \\
\hline \hline Phillips-Perron test statistic & & -2.609940 & 0.1141 \\
\hline Test critical values: & 1\% level & -4.004425 & \\
& 5\% level & -3.098896 & \\
& 10\% level & -2.690439 & \\
\hline \hline
\end{tabular}


ADF statistic $>5 \%$---- $(-2.6099)>(-3.0988)$,absolute factice value is bigger than critic value and in this case we proved that series is stationary, base hypothesis that series is not stationary it is not true. Since the above test series we proved the stationary, we are already able to perform regression analysis and assuming auto regression model.

\subsection{Regression analysis of the model}

Application of regression analysis and econometrics forecast of economic occurrences is accomplished through a process called stages of econometric analysis: 1. Formulation of the model, theory, economic hypothesis, 2. Specification of suitable economic model, 3. Data Collection, 4. Model evaluation, 5. Hypothesis testing, 6. Results interpretations.

Below are all analysed all stages by Eviews analysis, using CMSS (Common Method of small squares). The form of assumed model is:

$Y \_R=\beta 0+\beta 1 * \mathrm{GDP}+\beta 2 *$ Inflation $+\beta 3 * \mathrm{NoAB}+\beta 4 *$ Interest_Real $+u$

Precisely through the formulated model we want to prove the hypothesis:

Ho: The effect of macroeconomic factors is not important in gross loan portfolio of MFIs

H1: The effect of macroeconomic factors it is important in gross loan portfolio of MFIs

ThroughEviews, are realized several types of models, and we have achieved the best model as is shown below:

$Y \_R=0.1789+0.0150 *$ GDP $-0.0023^{*}$ INFLATION + 0.0122*NAB - 0.0323*INTEREST_REAL + u

Interpretation of parameters:

$\checkmark \quad 0.1789$ shows that even when all independent variables are one, yield on gross portfolio will increase by 0.1789 .

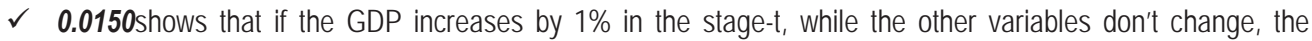
probability ofyield on gross portfolio is expected to increase by $0.0150 \%$.

$\checkmark(-0.0023)$ shows that if the inflation for the stage-t increases by $1 \%$ while the other variables don't change, the probability of yield on gross portfolio is expected to decrease by $(-0.0023) \%$.

$\checkmark \mathbf{0 . 0 1 2 2}$ shows that if the number of active barrowers of microfinance for the stage-t increases by $1 \%$ while the other variables don't change, the probability of yield on gross portfolio is expected to increase by $0.0122 \%$.

$\checkmark(-0.0323)$ shows that if the real lending interest rate for the stage-t increases by $1 \%$ while the other variables don't change, the probability of yield on gross portfolio is expected to decrease by $(-0.0323) \%$.

The regression coefficient sign complies with the economic logic which means that the link between the variable is constant.

$\boldsymbol{R}^{2}$ thecoefficient of determination is 0.7839 shows that $78.39 \%$ of the total variation (\% of the probability of yield on gross portfolio) is determined by the variation caused by four factors that we have identified in the model. $R$-Correlation coefficient is $\mathrm{R}=\sqrt{0.7839}=\mathbf{0 . 8 8 5 3}$,an indicator that is close to 1 , which indicates a strong positive linear relation between yield on gross portfolio and independent variables. Some comparison criteria are used in achieving the above model: 1 . The coefficient of determination $R^{2}$, 2. The adjusted coefficient of determination $R^{2} g j$, 3. AkaikeCriteria, 5 . Shwarc Criteria.

All the criteria mentioned above, estimated in the model for the $5 \%$ significance level, resulted better, which means $\mathrm{R}^{2}$ and $\mathrm{R}^{2}$ adjust have higher values and Akaike and Schwarz criteria have smaller values. Also in the evaluation of the model are taken into consideration the evaluation of regression coefficients and model in general.

The whole model results important ProbFstatist $=0.0011<0.05$

The whole coefficients result important, their prob $<0.05$.

That model to be available should satisfy a condition that arises from the use of CMSS (Common Method of small squares).

In determining if the error term is normally distributed or not is using JarqueBera test, which clearly show that $\mathrm{JB}=0.64$ $X^{2} 0.05,5=11.07$, we tested that the actual value of JB is 0.64 and the probability to earn the value is 0.72 . So, the actual value is less than the critical hi-meters $(0.64<11.07)$, which means that the basic assumptions remain, the error term is normally distributed, and therefore a linear selected model acceptable.

In evaluating the Heteroskedasticity used the White test, where by Eviews we got these results:

Heteroskedasticity Test: White

\begin{tabular}{llll}
\hline \hline F-statistic & 0.780126 & Prob. F(14,1) & 0.7234 \\
Obs*R-squared & 14.65792 & Prob. Chi-Square(14) & 0.4019 \\
Scaled explained SS & 5.974032 & Prob. Chi-Square(14) & 0.9671
\end{tabular}


From the assessment of Heteroskedasticity we see that the probability is 0.72 and is greater than $(0,05)$, therefore Ho is accepted. That does not have Heteroskedasticity.

It is also proved that the error term has no serial correlation, and for this is used the Breusch-Godfrey serial correlation LM Test, from where we have that $F=N * R 2=3.30, \operatorname{CrVL}=\chi 2_{0.05,5}=11.07, \mathrm{~V} \mathrm{~F}<\mathrm{Crv}$, Ho stands, the term error through LM test shows that there is no autocorrelations.

\begin{tabular}{lcll} 
Heteroskedasticity Test: Breusch-Pagan-Godfrey & & \\
\hline \hline F-statistic & 0.717259 & Prob. F(4,11) & 0.5975 \\
Obs*R-squared & 3.309860 & Prob. Chi-Square(4) & 0.5074 \\
Scaled explained SS & 1.348978 & Prob. Chi-Square(4) & 0.8530 \\
\hline \hline
\end{tabular}

Since we have proven that the chosen model is a good model and the impact of macroeconomic factors is important, then we are able to estimate ARIMA model for yield gross portfolio.

Before we begin with the analysis of the ARIMA model, the yield of the loan portfolio of MFIs correlogram chart is created using Eviews.

\begin{tabular}{|c|c|c|c|c|c|}
\hline Autocorrelation & Partial Correlation & $\mathrm{AC}$ & PAC & Q-Stat & Prob \\
\hline$* *$ & ${ }^{* *}$ & $1-0.276$ & -0.276 & 1.4577 & 0.227 \\
\hline$\cdot 1^{*}$ & $\left.\cdot\right|^{*}$ & 20.202 & 0.137 & 2.2998 & 0.317 \\
\hline$\left.\right|^{*}$ & . $1^{*}$ & 30.092 & 0.197 & 2.4893 & 0.477 \\
\hline${ }^{* *}$. & ${ }^{* *} \mid$ & $4-0.248$ & -0.236 & 3.9615 & 0.411 \\
\hline & ${ }^{*}$ & 50.004 & -0.199 & 3.9619 & 0.555 \\
\hline
\end{tabular}

From the above table it seems that the autocorrelation gradually diminishes and the partial autocorrelation decreases after the first step, therefore, it is likely the AR(1) model. Whereas, if we were to refer to a MA process, then it could be MA(2) model, because the autocorrelation becomes zero after the second step, while the partial autocorrelation decreases quite fast.

By Eviews we have assessed ARIMA model, which is an ARIMA $(1,1,2)$ :

$Y \_R=0.132+[A R(1)=0.633, M a(1)=-0.888]$

Interpretation:

I (1) The Series became integrable in the difference of the first order chain; exactly this consists with Philip Peron method, in which since in the first difference the series was stationary.

AR (1) have autocorrelation of the first order, coefficient near its results important, showing that prior period explain the variation of the yield gross portfolio for the current year.

MA (1) and in the case of sliding average coefficient beside her turns important.

As was highlight above evaluation criteria for the best model such as Akaike and Schwarz coefficients resulting in a lower level compared with other models. R2 and R2 adjusts have higher levels, it allows us to say that the build model is the best one, and suitable for short-term forecasts and also have confirmed that the probability of the model as a whole is significant at the $5 \%$ significance. However determination coefficient is R2 $=56.05 \%$, show a low level and we cannot successfully use the previous values of the series in order to make predictions with a high degree of accuracy.

\section{Conclusion}

Nowadays, microfinance is not presumed as a "magical bullet" that helps poverty reduction, but microfinance focuses it is "poverty graduation" of poor families by offering a range of services and financial products. Microfinance it is not an isolated system of informal financing assets but a specific element of the financial system and an engine of economic growth.

Microfinance in Albania in the recent years has been growing steadily. Microfinance institutions have increased the gross loan portfolio by $5.6 \%$ and the number of clients served. Given the importance of MFIs have on a country's economic development and its direct and indirect impact on economic and financial development, we have analysed the impact of macroeconomic factors on gross portfolio of MFIs in Albania.

In this study we have presented a different approach, presenting in detail the statistical and econometric analyse of variables evaluation. Through statistical and econometric analyses we have evaluated the reliability and validity of the model, where the data obtained have shown that the supposed model is an important model and macroeconomic factors 
have an impact on gross loan portfolio's performance. The study and data obtained will be useful for the development partners, because they will offer an overview of the effects of the macroeconomic factors on MFI's performance, also encouraging further studies about the impact of microfinance in developing country.

\section{References}

Ahlin Ch., Lin J. (2006): Luck or Skill? MFI Performance in Macroeconomic Context. BREAD Working Paper No. 132. Bureau for Research and Economic Analysis of Development, Centre for International Development, Harvard University.

Ahlin Ch., Lin J., Maio M. (2011): Where does microfinance flourish? Microfinance institution performance in macroeconomic context. Journal of Development Economics, 95: 105-120.

Esmeralda Doçi "Microfinance and the interaction of macroeconomic factors in poverty reduction." Academic Journal of Interdisciplinary Studies, Vol 5, No 2, July 2016.

Esmeralda Doçi, Dori Risilia, Ina Pagria (2014). Macroeconomic situation and quality indicators of loan portfolio, its econometric analysis. Financial Challenges of Growth, Sustainability and Visionary progress of The Regional Economy (p. 125). Tiranë: Albanian Center for Risk.

Fouillet C., Augsburg B. (2010): Profit empowerment: The microfinance institution's mission drift. Perspectives on Global Development and Technology, 9: 327-355.

Janda K., Svarovska B. (2013): Performance of microfinance investment vehicles. Journal of Economics, 61: 47-66.

Janda, Karel, and Pavel Zetek. "Macroeconomic Factors Influencing Interest Rates of Microfinance Institutions in Latin America and the Caribbean." Agricultural Economics-Czech 4.60 (2014): 59-173.

Jeniček V. (2011): International indebtedness of developing countries. Agricultural Economics - Czech, 57: 57-63.).

Maksudova N. (2010): Macroeconomics of Microfinance: Hoë Do the Channels Work? Working Paper Series No. 423. CERGE-EI, Prague.

Osmani Myslym. Econometrics with its aplplication. Tirane, 2010.

\section{ANEX}

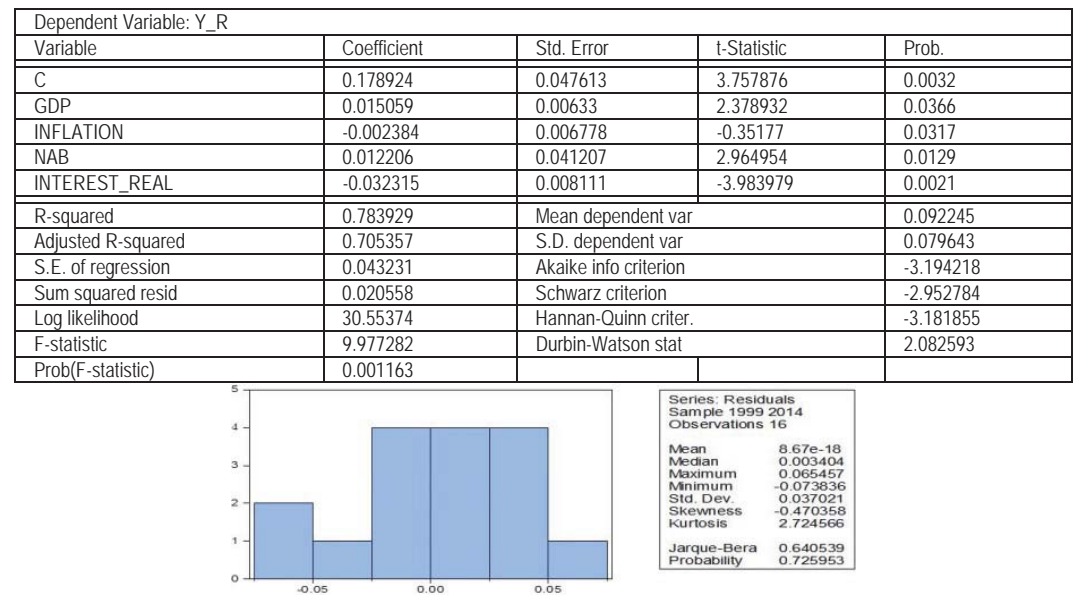

Dependent Variable: Y_R

Method: Least Squares

Sample (adjusted): 20002014

Included observations: 15 after adjustments

Convergence achieved after 28 iterations

MA Backcast: 19981999

\begin{tabular}{|l|l|l|l|l|}
\hline Variable & Coefficient & Std. Error & t-Statistic & Prob. \\
\hline C & 0.132922 & 0.023173 & 5.736079 & 0.0001 \\
\hline AR(1) & 0.633986 & 0.226137 & 2.803546 & 0.0159 \\
\hline MA(2) & -0.888593 & 0.070722 & -12.56464 & 0 \\
\hline R-squared & 0.56052 & Mean dependent var & 0.098395 \\
\hline Adjusted R-squared & 0.487273 & S.D. dependent var & 0.078407 \\
\hline S.E. of regression & 0.056144 & Akaike info criterion & -2.744953 \\
\hline Sum squared resid & 0.037825 & Schwarz criterion & -2.603343 \\
\hline Log likelihood & 23.58715 & Hannan-Quinn criter. & -2.746461 \\
\hline F-statistic & 7.652486 & Durbin-Watson stat & 2.208796 \\
\hline Prob(F-statistic) & \multicolumn{3}{l}{} & \\
\hline Inverted AR Roots & 0.007205 & & \\
\hline Inverted MA Roots & .63 & & \\
\hline
\end{tabular}

